\title{
DEVELOPMENT MANAGEMENT AND FORECASTING IN A GREEN INNOVATIVE ECONOMY BASED ON THE INTEGRAL DYNAMICS MODEL IN THE CONDITIONS OF "INDUSTRY - 4.0"
}

\author{
Sultan Ramazanov ${ }^{1}$, Mariana Petrova ${ }^{2}$ \\ ${ }^{1}$ Kyiv National Economic University named after Vadim Hetman, Kyiv, Ukraine \\ ${ }^{2}$ St. Cyril and St. Methodius University of Veliko Tarnovo, Veliko Tarnovo, Bulgaria \\ e-mails: ${ }^{1}$ sramazanov@i.ua, ${ }^{2}$ m.petrova@ts.uni-vt.bg
}

Received: 01 January 2020; Accepted: 13 March 2020; Published: 01 May 2020

\begin{abstract}
In modern conditions of instability, systematic crises and global transformations the problem of developing methods and technologies for analysis, modeling, management, forecasting and decision making for stable development of viable socioeconomic systems has become the most important. These systems are characterized by complex structure and behavior, the synergison and non-linearness and have all sorts of "NOT" and "MANY" factors characteristics. The study of model's systems, which include in their structure the humanitarian component (socio-ecological, economic and humanitarian subsystems - SEEHS, i.e. it is aspect of integration of 4 spheres) as a system of the noosphere type, is very actually problem. The greens innovations economics in the conditions of "Industry - 4.0", such as man-made integral industrial systems, are systems of type SEEHS. The peculiarity of the processes of stable development management, prediction and maned decision-making in the modern conditions of socio-economic, ecological, social and humanitarian crises, and the system crisis as a whole, as well as in the conditions of necessity and importance of stable and safe development of industrially of economic structures consists in accounting of the influence of uncertainties as on the object of control as well as and behavior of decision-makers. The there has been proposed models and control technologies of viable, stable and safe development of SEEHS systems based on the integrated "object and subject" oriented approach, a conceptual model, a generalized model of the synergistic dynamics with the regard of the uncertainties of on both stochastic and chaotic factors, of on base nonlinear dynamic and others.
\end{abstract}

"Linear thinking is useless in a non-linear world"

Key words: integral, model, development, management, prediction, innovations economics.

JEL classification: C02; Q01; Q57

How to Cite:

Ramazanov, S. Petrova, M. (2020). Development management and forecasting in a green innovative economy based on the integral dynamics model in the conditions of «Industry - 4.0». Access journal, ACCESS Press, 1(1): 9-30, DOI: https://doi.org/10.46656/access.2020.1.1(1)

\section{INTRODUCTION}

The main scientific and technological driving factors in the 21 century will be innovation development following super technologies: Artificial Intelligence, Nano-Technology, Bio-Media Technology, Cognitive technology and Socio-Humanitarian technology. More specifically, this is the modern development of Innovative Technologies: «NBIC» $+«$ SHT» or NBICS- convergence.

Technology convergence is a functional / integrator of «NBIC+SH»-technologies. NBICS- convergence is a technology integrator (Ramazanov \& Burbelo \& Vitlinsky et al, 2012), i.e. functional aggregator, which 
is based on synergistic and systemic synthesis and structural implementation. Each of the components of convergence (integrator) is positioned as a subsystem / component with its corresponding function, potential and scope. NBICS is integration: Nano-, Bio-, Info-, Cogno- and Socio- - subsystems. The structural structure of society is the functional basis of its self-organization. Actual examples of social aggregation are the institutions of education and health care, which function effectively both offline and in the context of convergence of common tasks. Thus, NBICS - convergence as a functional integrator works as a single system with five main subsystems. Substrate, synthesizing, distributive, cognitive and social aggregation stimulate synergistic manifestations of convergence. At the same time, manufacturability, the ability of the subsystem to work as an appropriate technology (for example, nanotechnology, information technology, etc.) are also important. In general, the NBICS integrated model is aimed at a unified system support for the efficient operation of systems based on NBICS- convergence. In addition, through the sociocomponent, a paradigm link is established between natural-scientific and social-humanitarian knowledge. However, a more accurate integration is NBIC + SH (Ramazanov et al., 2019). Since complex technical, socio-economic, ecologic and social processes are generally non-linear, they are often unstable. In studying nonlinear systems, the researcher is often interested not so much in the time of development of the corresponding instabilities as in the time of evolution or development of unstable systems, that is, the time of arrival of the system, after all, to some limit state. The limiting state of the system often has attracting properties called attractors.

When studying complex nonlinear systems, to understand a very complex process, one sometimes chooses a very simple system from any field whose behavior is similar or qualitatively resembles the behavior of the system being studied. By studying the properties of a simple system, they find those general characteristics of behavior and inference that are almost independent of the details of the model, and these general conclusions are used to analyze the behavior of much more complex systems, transferring knowledge from one, simpler system to another, more complex. In addition, because in complex nonlinear systems there is a process of self-organization, it is possible to apply simple models and theories to complex nonlinear systems. However, it should be noted that in complex nonlinear systems there are many degrees of freedom, but in the process of development (evolution) can be distinguished by several defining measures of freedom, which are attached to all others. These defining measures of freedom of nonlinear systems are called order parameters. If these parameters are few, then it becomes possible to describe a complex system relatively simply.

Synergetics, or self-organization of complex systems, relies on the nonlinearity, openness and dissipation of systems. Nonlinear open dissipative systems are assumed to underlie most complex biological, social, technical, physical, and other phenomena. Today, humanity is aware of the threat posed by natural disasters, natural and man-made disasters, conflicts in society, wars and the like. To prevent natural disasters, catastrophes, conflicts, wars, and other emergencies, the potential of modern science must be harnessed. It is necessary to create an international approach to the problem, which can be called risk theory, on the basis of 
which risk management is possible. Today, there is an urgent need in the world to anticipate and mitigate emergencies. The task is to create a new paradigm in the field of hazard or risk management, and to construct a mathematical theory of safety and risk based on nonlinear dynamics and computer simulation. On the basis of systematic analysis and nonlinear dynamics, patterns of catastrophic behavior of most complex systems in the field of technosphere, economy and the like can be revealed.

Nonlinearity, synergetics, crisis. Comparing the major technologies of the XX and XXI centuries, we see a fundamentally important new element. Strategic objectives of the XX century were solved by the use of technologies based on the knowledge of physics, chemistry, mathematics, mechanics, computer science.

New technologies are interdisciplinary. They require, on the one hand, knowledge of man and rely, of course, on knowledge of man. On the other hand, they present specific forecasting and design methods that imply quantitative description, the use of formalized models and methods of applied mathematics. On the other hand, they require a comprehensive description of the object, its relationship with the biosphere, technosphere, with scenarios of technological development. To do this, it is necessary to build on the solid foundation of science. One of the most successful and productive interdisciplinary approaches is selforganization theory or synergetics.

Synergetics considers so-called nonlinear and unstable systems. Nonlinearity means paradoxical, antiintuitive behavior of objects (when the joint action of several causes or factors can give new quality, when the result of their action cannot be calculated as the sum of the results of these reasons separately), which are studied. Nonlinear systems are characterized by several development scenarios, several options for the future. Instability is characteristic of systems that are far from equilibrium, and means that small deviations in such systems can build up, moving the object being studied to another state.

Economic, social, structural, systemic and current crises in the past are one of the manifestations of the nonlinearity and instability of the respective systems. Therefore, it is natural to speak about them in the language of synergetics.

The idea that after the works of Kondratiev, Schumpeter and other authors in the theory of social development - economics, history and other sections - some theory of cycles emerges. It is too early to talk about the creation of such a theory - as long as there is only a description of the phenomenon of fractality (not of cyclicality, but of fractality). Often found, the particular role of cyclicality is premature. The most significant result of N. Kondratiev is probably proof of the ineligibility of direct linear extrapolation, even at the level of statistics; the economic process is a substantially non-linear phenomenon, moreover, it is a process of self-organization of a complex dynamic system. Kondratiev was able to identify the factor that determines the transition to the bifurcation state of one of the components of this process of conjuncture. Does not follow Kondratiev et al. the authors so indisputably talk about predictions based on "cyclicality". It can only be a forecast of trends and the possibility of anticipation of the crisis. Not more ! In times of crisis, memory of a complex nonlinear system sharply decreases and factors of a stochastic nature begin to play a special role; the post-crisis state is almost unpredictable (Ramazanov \& Nagyon \& Crystal \& Stepanenko, 
2009; Ramazanov \& Rogoza \& Musayeva, 2010; Ramazanov \& Levasheva \& Stepanenko et al., 2011; Ramazanov \& Burbelo \& Vitlinsky etc., 2012; Levashova, 2011B, Koval et al, 2019).

In order to increase the competitiveness of enterprises at the beginning of the second decade of the XXI century enhanced integration of «cyber-physical systems» (CPS) into factory processes has begun.

The era of the «Industry 4.0» concept has come. The «Industry 4.0» concept provides for the full digitalization of all physical assets and their integration into vertical and horizontal value chains. It also involves digitizing products and services and developing digital business models, as well as providing customer access. CPS is in high demand among multinational companies such as Siemens, Cisco, Thyssen Krupp, who benefit most from the «Industry 4.0» concept. At present, «Industry 4.0» is gradually taking over the whole world.

The favorites of "Industry 4.0" will be biotechnology, nanotechnology, robotics and mechatronics, new medicine and new environmental management, development and use of personality and team capabilities at a new, higher level. About development, reforms, modernization, innovative technologies and what the world is transitioning today, moving to the sixth technological way, that is, to the NBIC (nano-, bio- , info- cogni-) technologies (Ramazanov, 2018). And socio-humanitarian technologies (SHT) refer to a person, to practice, to society ... to of moral, morality, to of culture. And this is more of a philosophical problem. That is, now we have to focus on $\mathrm{NBIC}+\mathrm{SH}-$ technology $(\mathrm{NBIC}+\mathrm{SHT})$. From here it is clear which executives we need, what personnel we need to prepare. We are on the threshold of a new revival in science and technology, based on a comprehensive understanding of the structure and behavior of matter from the nanoscale to the most complex of open systems, the human brain. The unification of science, based on the unity of nature and its holistic study, will lead to technological convergence and a more effective social structure to achieve human goals. The phrase "convergent technologies" refers to a synergistic combination of the four major "NBIC" (nano-bio-info-cogni) fields of science and technology, each of which is currently progressing rapidly.

Thus, on the basis of a synergistic approach, the issue of exacerbation of global crises generated by technogenic civilization is considered, and the question arises: is it possible to overcome these crises without changing the basic system of values of technogenic culture? This value system will have to change that overcoming global crises will require a change in the goals of human activity and its ethical regulations. Humanity has a chance to find a way out of global crises, but it will have to go through an era of spiritual reformation and the development of a new value system.

The modern paradigm of the global community's transition from a systemic crisis and the transition to a secure and sustainable development is, first and foremost, an innovative way of development based on modern innovative, information and convergent technologies, based on new knowledge as the main resources of development, based on socio-humanitarian technologies, as well as on the basis of active transition according to the 6th, and then to the 7th technological way of development and "Industry 4.0". 
The modern vector of civilizational sustainable development of society requires the intensive implementation and dissemination of global technologies: nano-, bio-, information and communication technologies and convergent technologies, as well as the development of socio-humanitarian technologies. (Arshinov \& Budanov, 2016; Chuprov, 2012; Roco \& Bainbridge \& Tonn etc.; Babkina, 2017; Melnyk, 2017; Kapitsa, 2018; Ramazanova et al, 2019; Kovalchuk \& Naraikin \& Yatsishina, 2013; Lecturer, 2011; Melnyk, 2015; Kazantsev \& Kiselev \& Rubvalter \& Rudensky, 2012; Levashova, 2011A, Gryshova, 2019).

Note that cognitive technologies are global-level technologies, the transforming effect of which gives a new quality to interacting elements and leads to the formation of a fundamentally new technological platform for sustainable economic development. The increase in the intellectualization of industrial production contributes to the fact that the distinguishing features of enterprises are: significant individualization of products in the conditions of high flexibility of large-scale production; the integration of consumers and manufacturers in the framework of end-to-end processes throughout the product life cycle and value chain; integration within the framework of production networks of information and data reflecting all aspects of requirements, design, development, production, logistics, operation, service, etc., i.e the creation of "industrial intelligence"; globalization of product / product development teams, as complexity of products requires a variety of competencies; the formation of a network production "ecosystem" due to cooperation and lowering barriers between enterprises and customers; the development of "cloud" technologies as a way to implement customized production by order; use of production capabilities of virtual production networks on the basis of integrated production sites, their support with special software; isolation and accumulation of non-material functions, such as research and forecasting of the market and demand, formation of a product concept, formation of technical requirements, etc.; because non-material components occupy an increasing share in the cost and price of the finished product; the formation of the market value of enterprises through the knowledge of employees, know-how, high technology, inventions, industrial designs and other intangible assets.

A qualitative change in factors of production puts forward a set of interrelated tasks for industrial enterprises: integration into «Industry $4.0 »$, increasing the continuity and flexibility of production, transition to flexible production systems that ensure the adaptation of production infrastructure to innovative activities, changing market requirements requires different approaches to the composition and configuration of key production factors; increasing the consistency in the duration and productivity of all interconnected divisions of industrial enterprises causes the recording of results not only at the place of application of production factors, but also in related divisions from the position of their influence on the economic performance of enterprises; a rational increase in the growth of $R \& D$ costs, which ensures the implementation of scientific and technical policies directly in the process of scientific and industrial activity, determines the assessment of their relationship with the share of revenue from new types of products; the uncertainty of the economic situation, high risks in the development of innovative products create the prerequisites for the development 
of economic and mathematical models that are adequate to the object of study and can improve the quality of industrial enterprises.

Thus, the steady economic growth of modern industrial enterprises is determined not so much by the number of personnel as the presence of workers who are able to carry out scientific and technological developments at the modern level, create competitive products and services based on them, offer new ways of organizing production, and determine the formation of new technological trends development in a market environment. In this regard, a different system of productive forces is needed that exceeds the capabilities of the industrial type of production and other ways of combining living and materialized labor.

The convergence of intellectual resources and information technology as a productive force leads to the emergence of new types of factors of production - cognitive factors of production - which are understood as specific, hard-to-simulate resources of an industrial enterprise that allow you to create a product that is in demand on the market. Connectiveness as a scientific and cognitive action is moving into a new quality, providing the appropriate knowledge for complex research.

Artificial intelligence, neurocomputers, technologies of various interfaces based on the use of the properties of the human brain is a fundamentally new environment for human production. The use of cognitive principles in the economy allows us to bring the basic production processes to an intellectually new level.

«Green technologies» and «Green economics». Nowadays, the spread of digital technologies: 3D modeling, 3D scanning, volume printing and robotics, as well as artificial intelligence systems and technologies has become a powerful factor that has given a new impetus to progress towards the growing needs of mankind. But in order for an innovative product to organically fit into the multidimensional space of the future, at the present stage of development of society, the environmental component of any innovation comes to the fore, that is, innovation, among other things, must be environmentally acceptable. According to many experts, environmental technologies, colloquially called "green technologies", will become leaders in the development of the world economy in the 21century. Expert opinions did not appear from scratch - in recent years, in the context of the implementation of the environmentally-oriented growth strategy, "green technologies" in the civilized world are developing at an accelerated pace and the answer to this challenge has been a new scientific direction and practice called "green technologies".

It is worth noting that there is no single definition of the concept of "green" or environmentally friendly technologies. The general approach implies the achievement of their main goal - to reduce the negative impact on the environment by reducing the amount of resources consumed, reducing the amount of waste up to their full return to production through deep processing, using models, technologies and principles in production processes, especially nature-like tools to increase quality and environmental safety.

"Green technologies" essentially cover all areas of human activity and are aimed at: sustainable development of modern society for the benefit of future generations with the solution of global problems, preventing the depletion of resources, establishing sound environmental management, improving 
demography, eliminating toxicity of production; maximum waste reduction due to innovations in technology and consumption patterns; fundamental modification of hazardous industries and their replacement with harmless ones using natural technologies created by nature; replacement of non-renewable natural resources with alternative renewable sources of raw materials and energy; the exclusion of the use of harmful synthetic chemicals in agriculture, the introduction of biotechnology in agriculture, animal husbandry and the processing of agricultural products.

Currently, "green technologies" are being introduced into the entire chain of companies, including, in addition to production, consumption, management and methods of organizing production, in the name of solving global problems for the sustainable development of modern and future society, namely: modification and replacement of harmful industries; development of new alternative types of energy and new types of fuel; the search for new approaches to safe and affordable food and water; protection against pollution of the atmosphere, soil, fresh water and the oceans; prudent regulation of demography.

"Green technologies" is a vivid manifestation of the current trend in the effectiveness of an interdisciplinary approach to solving complex problems. They do not replace, but combine ecology, economics, social technology, based on all modern achievements of science and technology. Therefore, one of the most important areas of modern development of scientific and technological progress is a paradigm shift: from extensive to sustainable development. The most pressing global environmental problems today include climate change, access to quality water and other resources, loss of biodiversity, so we can assume that the development of technologies will be aimed at solving them. "Green technologies" are both environmentally friendly raw materials, and environmentally friendly end products, and environmentally friendly production.

Humanity has come to the point where modern civilization, called technogenically-consumer, has become deadlocked when it is necessary to seriously examine its grounds and consciously choose an innovative, socio-environmental, spiritual-moral and socio-humanitarian development strategy; otherwise, humanity may disappear from Earth as a result of today's global and systemic crises and catastrophes. The evolution of humanity as a global system, like the evolution of any open nonequilibrium system, obeys the laws of nonlinear dynamics and synergetics (Schwab, 2016; Kapitsa, 2018; Ramazanov, 2018; Ramazanov\& Burbelo \& Vitlinsky etc., 2012).

The merger of artificial intelligence, robotics, the Internet of Things (IoT), autonomous vehicles, 3-D printing, blockchain, biotechnology is driving the fourth industrial revolution, that is, «Industry 4.0».

The digital economy has created an enabling environment for the introduction of «Industry $4.0 »$ as a new level of production organization and value chain management throughout the life cycle of products.

The modern paradigm of the world community's exit from the systemic crisis and the transition to safe and sustainable development is, first and foremost, an innovative way of development based on modern innovative, information and convergent technologies, based on new knowledge as the main resources of 
development, based on socio-humanitarian technologies, as well as on the basis of active transition according to the 6th and then to the 7th technological way developmental and «Industry 4.0».

In today's difficult conditions and with the development of the modern economy, there is a need to consider the problems of its forecasting in a new way. This is due to the growing impact of the globalization processes and factors of uncertainty and risk on the economy and the performance of individual countries and regions. Existing methods and forecasting models rely heavily on the use of econometric models; Particular importance is forecasting on the basis of random processes, including within the framework of stochastic dynamic models of general equilibrium. These stochastic models of economic growth are based on the growth paradigm, which greatly reduces the possibilities of their application in the conditions of a change or a change in the trend of economic development. Nowadays, the increasing influence of current risk factors on the state of the economy and society is observed, which generates a violation of its relative stability and leads to a significant reduction of the influence of factors and conditions of past years on the trends of economic development in the long run.

This paper analyzes the possibilities of forecasting development based on the approximation of the integral stochastic growth model in the form of recurrent equations, which are formed taking into account the properties of the increments of the Wiener random processes. It takes into account only the current or initial state of the economy (Ramazanov \& Stemplewska, 2017).

We note that for simulating economic growth, initially, similar deterministic ratios were used. Later, the staging of growth models was associated with the introduction of various shock variables taken into account in the form of random processes. Due to the complexity of the methodological, mathematical, informational nature, an integrated model of sustainable development of the socio-ecological-economic system has not yet been created, suitable for all levels of governance. Therefore, only the creation and integration of various econometric, balance and optimization models, as well as models of nonlinear dynamics and neural network modeling into a single system give an opportunity to comprehensively describe the interconnections and trends of the development of the whole global system in the conditions of market and mixed economic relations. Only the integration of socio-economic, ecological, cultural-spiritual, and other processes modeling methods will ensure the stability and viability of the whole system (Ramazanov\&Sergienko, 2014; Ramazanov, 2015; Ramazanov, 2008; Ramazanov et al, 2012).

In today's difficult conditions of nonlinearity, instability and systemic crises the increasingly decisive role in the growth of the national economy is given by the achievements of science, technology and education embodied in innovation. It is innovations, as the decisive result of scientific and technological progress, stimulate the growth of productivity and efficiency of the use of factors of production, improving the quality and competitiveness of the country's products. From the middle of the twentieth century the government of the leading countries of the world, which belong to the developed countries of the world, took an open course on innovation, creating an innovative economy, combining the intensification of scientific and 
technological progress (STP) with institutional transformations in the economy and the public administration, aimed at improving the quality of organization and management of the economic system.

Scientific and technological progress as a continuous and systematic process of introducing into the economic practice the results of the development of science and technology, as well as new methods of organization of production and labor affects economic growth and development in several ways: first, the improvement of technologies allows you to increase the gross output without changing the aggregate costs; and secondly, the technological transformations of production lead to a change in the structure of products produced in favor of high-quality goods and services with high added value; Thirdly, STP causes major changes in objects and means of labor; Finally, STP makes a significant contribution to improving the wellbeing of society and the quality of life of the population.

However, in the simulation of ecological and economic development in line with the concept of environmental modernization and the principle of sustainable development, the following interconnected systems must be taken into account: economics (production), labor (population), resources (minerals, natural resources, etc.), nature (this system reflects the state of the environment), and it is also important to take into account the achievements of the STP and the level of education.

Consequently, the development and research of integrated stochastic models based on the use of mathematical methods, models and innovative technologies in order to predict the nonlinear stochastic dynamics of ecological-economic and social-humanitarian systems in the current conditions of uncertainty and risks is an urgent problem (Vagapova, 2007; Galitsin \& Ramazanov, 2017; Grigorkiv, 1999).

\section{The purpose of the work.}

The problem of modeling, forecasting, optimal stochastic management/control and decision-making in socioecological-economic systems with humanitarian components, i.e on the basis of integration of 4 spheres of activity and functioning of modern complex systems in the innovative economy (represented both in phase space and in space ESTI ("education - science - technology - innovation"), as well as in modern science in general, is the main and relevant. The purpose of this work is to develop and study the integral socio ecological - economic stochastic nonlinear model of the dynamics of technogenic objects and processes for forecasting the development of a green innovative economy. The proposed work is a development of recent studies by the authors. (Ramazanov \& Stepanenko \& Chernyak \& Tishkov, 2019; Ramazanov \& Stepanenko \& Tishkov \& Honcharenko, 2019).

\section{Presentation of the main results.}

In this work, technogenic objects and processes (TOP) refer to man-made industrial enterprises or technogenic regional production (TRP), or technogenic regions (TR), technogenic economic object (TEO), and others like that. We will devote all this as TOP. The review and analysis of some recent results obtained by various authors on macro- and micro-modeling of the dynamics of ecological-economic and socialhumanitarian systems (SEEHS) and processes that are related to the TOP, are functioning and developing under difficult conditions of nonlinearity, instability and crises. The conceptual model of the forecasting and 
management of ecological and economic processes, as well as the statement of the problem of optimal ecological and economic forecasting and management in the presence of "NOT - and MANY - factors" are presented in the author's work (Ramazanov et al, 2012; Grigorkiv, 1999). It also proposes a generic multiplicative - additive stochastic model with chaotic dynamics.

Most models of socio-ecological-economic systems (SEES) that were created earlier have theoretical and deterministic character and are quite problematic in terms of adequacy and availability of information, new knowledge and technologies for their implementation. In this regard, the task of controlling technogenic regional production (TRP) in the context of a crisis causes the objective need to improve methods, models and information technologies based on stochastic equations for the management of the SEES. (Ramazanov, 2015; Ramazanov, 2008; Ramazanov et al, 2012)

A general conceptual integrated model is proposed, a generalized synergetic model of dynamics is considered taking into account various uncertainties (stochastic and chaotic components). To predict the state of the green innovation economy, an integrated stochastic nonlinear model of growth dynamics in the phase space has been developed and investigated. The paper also examines the aspects of optimizing the management of modern complex systems that function and develop in the current conditions of instability.

An innovative model of sustainable and safety development of societies and the world as a whole should be built because of an integral paradigm of socio-ecological-economic unity and socio-humanitarian technologies. The following system as "Creator-Man-Socio-Humanitarian-Ecological-Economic environment" is the object for system analysis studying, synthesis, innovative technologies of modeling and management. At the same time, a global goal to ensure the safe existence and sustainable development of the entire world civilization is the research and development of integral models of the entire system with the following orientation structure (Fig. 1).

Here SHS - Socio - Humanitarian System; PS - political system; IT/S - innovative technologies and synthesis; $R(t)$ - input effects on the system(resources, specified regulatory functions, conditions, time and other restrictions); $\mathrm{Y}(\mathrm{t})$ is the integral output of the system(both "useful" and "harmful") (Ramazanov, 2012).

The concept of sustainable and safety development implies a change of the traditional economy paradigms, the humanization and ecologisation of its main principles, the search for common approaches and the consistency of concepts for the development of ecological and socio-economic systems. During recent years, a new interdisciplinary field of applied science has emerged it is an ecological economics. Ecological economics is a new field of research that deals with the relationship between natural ecosystems and socioeconomic systems in the broadest sense, relationships that are crucial for many current problems of humanity, as well as for building a sustainable and high-quality future.

Moreover, a very important problem is also the study of systems with integral properties, that is, systems that include socio and ecological economics and humanitarian subsystems (SEEHS) as systems of the future (noosphere type systems) in their structure. Local regional production systems such as technogenic industrial systems (TIS) are also SEEHS type systems. 


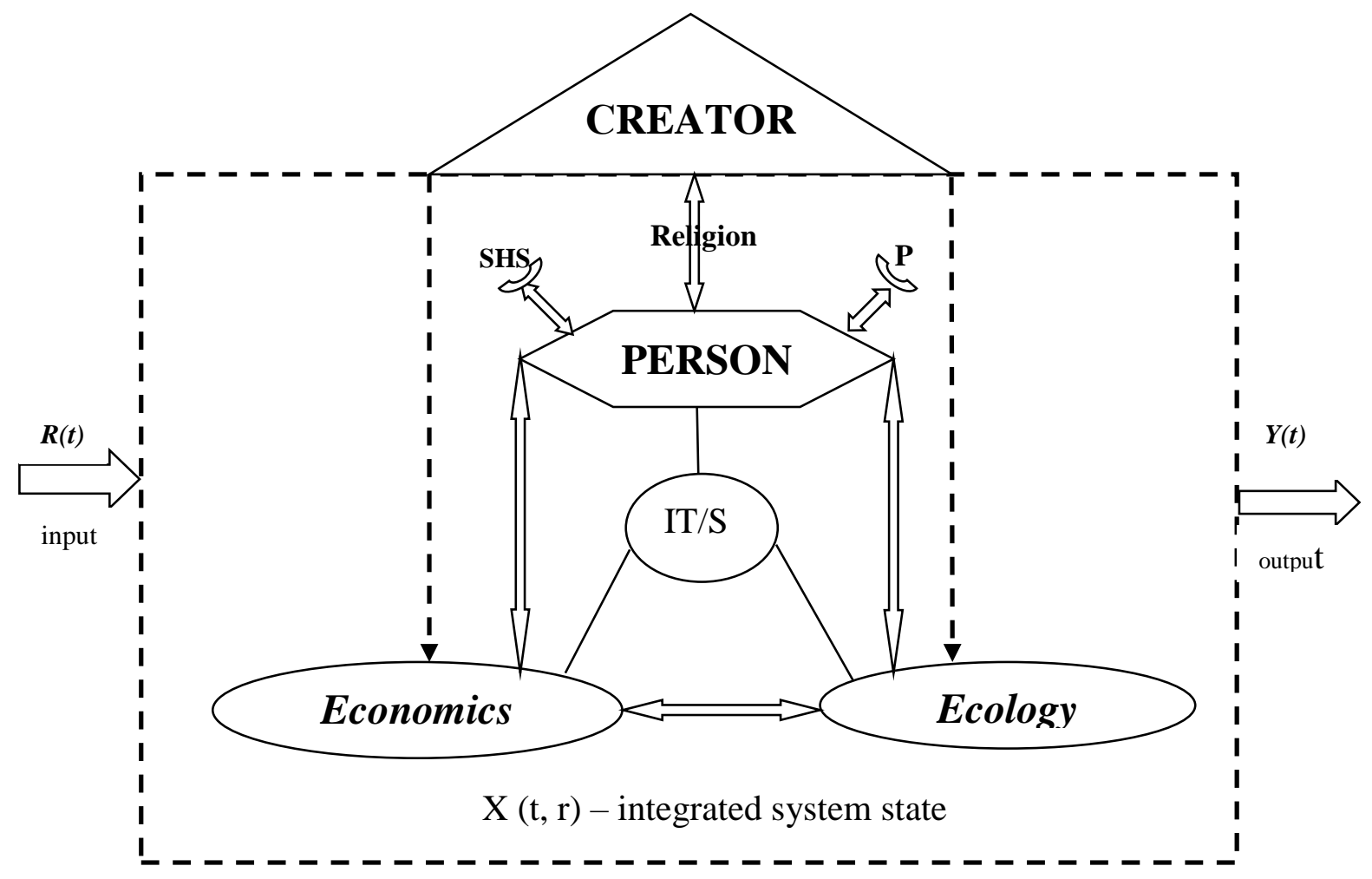

Fig. 1. An integrated model of sustainable development of global system (society, world civilization)

Therefore, there is a need to develop and apply models, methods and approaches that, from a single methodological approach, would allow us to analyze the behavior of a complex system, build a model of its development, predict its state and, on the basis of the data obtained, formulate control influences to ensure that the desired goals are achieved given restrictions and criteria. Because of this, it is important to systematize, analyze and develop new analytical models, methods and approaches to assessing the state and behavior of complex nonlinear stochastic dynamic systems, as well as demonstrating the possibilities of using them to solve the problems of managing systems of various nature, including social, economic, environmental, political, etc., operating under uncertainty.

The concept of sustainable and secure development of the state as a whole and of individual regions allows to ensure stable and balanced development of four sectors of activity: economic, ecological, social and spiritual and moral unity on the basis of innovative socio-humanitarian technologies, combining principles of eco- nomic efficiency, social protection and environmental safety.

Today, the most important scientific, technical and technological problem is the design and implementation of complex systems with the desired properties based on Integrated systems such as "SEEHS" and Converged technologies such as NBIC and, in particular, NBIC+SH, i.e. Integrated intelligent and hybrid systems such as $\left[S=\left\langle E_{c}, E_{n}, S_{o}, \mathrm{H}_{u} ; E S I T\right\rangle\right] \mathrm{U}[\mathrm{NBIC}+\mathrm{SH}]$.

The general scheme of the integration model of sustainable safe ecological, economic and sociohumanitarian development of the system can be represented as an integrator: 


$$
S=E_{n} \oplus E_{c} \oplus S_{o} \oplus H_{u} \oplus E S T I
$$

That is, as an integral "4-unit" system, and $E_{c}$ - the economic subsystem (production), $E_{n}$ - the ecosphere, $S_{o}$ - the social sphere, $H_{u}$ - the humanities, ESTI - (education, science, technology, innovation) or, in particular, R\&D (Fig. 2). (Ramazanov et al, 2009; Ramazanov, 2018; Ramazanov, 2019; Zerkalov, 2012; Zgurovsky\&Statyukha, 2007).

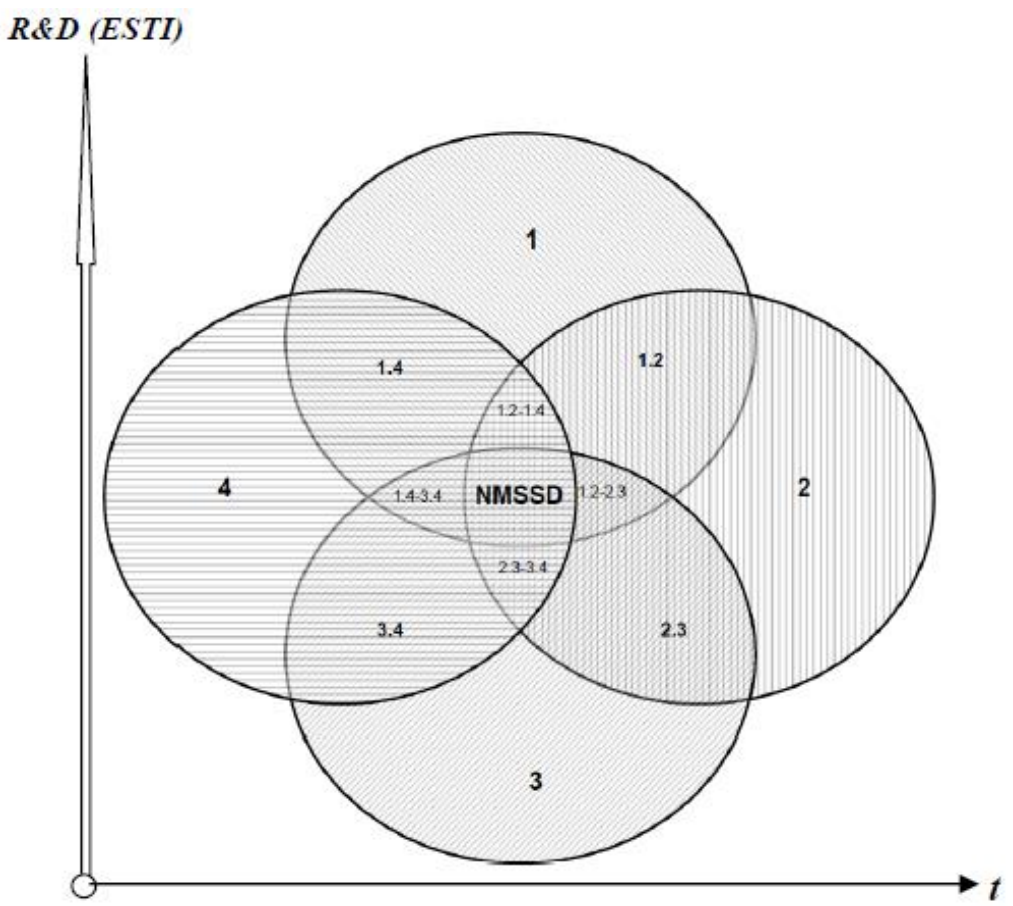

Fig. 2. 4 unite/sphere integrated system development diagram. Noosphere model of sustainable safe development (NMSSD) in space $(E S T I, t)$

Stochastic model of system dynamics with control vector. The principle of system dynamics of stochastic processes or the method of system dynamics in the presence of exogenous and endogenous stochastic effects can be represented as a stochastic differential equation (SDE): $\dot{X}_{j}=F\left(X_{j}{ }^{+}, X_{j}{ }_{j}^{-}, W_{j t}, U_{j t}\right)$, where $W_{j_{t}}$ is the standard Brownian motion; $U_{j t}$ - control vektor; $\sigma_{j}\left(X_{j}, t\right)$ - coefficient of variability (volatility) of growth. In particular, the stochastic equation of dynamics for $j$-th the factor (subsystem) can be represented as a differential equation:

$$
\dot{X}_{j}=\alpha_{j} X_{j}^{+}-\beta_{j} X_{j}^{-}+\sigma_{j}\left(X_{j}, t\right) d W_{j t}+b_{X j} U_{X j}(t)
$$

The stochastic term $\sigma_{j}\left(X_{j}, t\right)$ in the equation describes the influence of exogenous random factors. When adopting the notion of continuous-noise white noise, the equation of stochastic dynamics can be represented 
as: $\dot{x}=F(x, t)+\sigma(x, t) e(t)+b_{x} u_{x}(t)$, where $u_{x}(t)$ - control vector, $\{e(t), t \in T\}$ - white noise with continuous time.

To represent a stochastic nonlinear model of dynamics of a system in a discrete case, we can use the difference equation in the form (Ramazanov \& Sergienko, 2014; Osterm, 1970; Pshikhopov, 2009):

$$
x(t+1)=f(x(t), t)+w(x(t), t)+b_{x} u_{x}(t), t \in T,
$$

where $f$-conditional mean for $x(t+1)$ a given $x(t)$, and $w$ - a random variable with zero mean. If the conditional distribution $w(t)$ for a given $x(t)$ is a normal law, then the model can be rewritten as:

$$
x(t+1)=f(x(t), t)+\sigma(x(t), t) e(t)+b_{x} u_{x}(t), t \in T,
$$

where $\{e(t), t \in T\}$ - the sequence of independent equally distributed random variables with parameters $(0$, 1).

\section{Stochastic logistic model of development:}

$$
\dot{X}_{j}=A_{j} X_{j}\left(X_{j}^{0}-X_{j}\right) / X_{j}^{0}+\sigma_{j}\left(X_{j}, t\right) e_{j}(t)+b_{X j} U_{X j}(t), \quad j=\overline{1, k},
$$

where $X_{j}^{0}, X_{j}$ - accordingly, the maximum possible and the current value of the investigated value, and $X_{j}^{0}$ does not depend on time, and $\left\{e_{j}(t), t \in T\right\}$ - white noise with continuous time, $\sigma_{j}\left(X_{j}, t\right)$ - the coefficient of volatility.

\section{Integral model of dynamics with control}

As a result of complex formalization, we obtain one of the variants of the integral socio-ecologicaleconomic and innovation model of dynamics in the form of the following system of equations (1) - (12) (Galitsin \& Ramazanov, 2017; Solovyov, 2009).

\section{Model of systemic dynamics with control:}

$$
\frac{d}{d t} \Phi_{j}(\circ)=\alpha_{j} \Phi_{j}^{+}(\circ)-\beta_{j} \Phi_{j}^{-}(\circ)+\sigma_{j}\left(\Phi_{j}, t\right) d W_{j t}+b_{j} U_{j}(t) .
$$

\section{Capital model:}

$$
\frac{d}{d t}[K(t)]+\alpha K(t)=I(t)-C(t)-D(t)-B(t)+\sigma_{K}(K, t) e_{K}(t)+b_{j K} U_{j K}(t), K(0)=K_{0} .
$$

\section{Model of production function:}

$$
Y=F\left(K, L, R, e_{Y}(t)\right)=\left[\beta_{1} K^{\frac{\delta-1}{\delta}}+\beta_{2} L^{\frac{\delta-1}{\delta}}+\beta_{3} R^{\frac{\delta-1}{\delta}}\right]^{\frac{\delta}{\delta-1}}+\sigma_{Y}(Y, t) e_{Y}(t),
$$

\section{Release model for three assets:}




$$
Y(t)=A \tau(t)\left[\left(1-\alpha_{K}^{1}(t)-\alpha_{K}^{2}(t)-\alpha_{K}^{3}(t)\right) K(t)\right]^{\alpha_{1}}\left[\left(1-\alpha_{L_{2}}^{1}(t)-\alpha_{L_{2}}^{2}(t)\right) L_{2}(t)\right]^{\alpha_{2}}+\sigma_{Y}(Y, t) e_{Y}(t)
$$

The dynamics of all labor resources: $L(t)=L_{1}(t)+L_{2}(t)$, where $L_{1}(t)$ and $L_{2}(t)$ - respectively, the volume of skilled and unskilled labor resources,

$$
\frac{d}{d t}[L(t)]-\gamma L(t)=-\gamma_{Z} Z(t)+\gamma_{C} C(t)+\sigma_{L}(L, t) e_{L}(t)+b_{j L} U_{j L}(t),, L(0)=L_{0}
$$

The equation of dynamics of natural resources:

$\frac{d}{d t}[R(t)]-\gamma_{R} R(t)=\gamma_{K} K(t)-Y(t)-\gamma_{L} L(t)+\sigma_{R}(R, t) e_{R}(t)+b_{j R} U_{j R}(t), R(0)=R$,

or $\frac{d}{d t}[R(t)]-d(K(t), L(t), R(t))=\gamma_{K} K(t)-\gamma_{L} L(t)-Y(t)+\sigma_{R}(R, t) e_{R}(t)+b_{j R} U_{j R}(t)$,

Model of dynamics of total volume of pollution $Z(t)$ :

$$
\begin{gathered}
\frac{d}{d t}[Z(t)]+g(Z(t))=f^{*}(c, K, L, R)(1-\eta c)+\sigma_{Z}(Z, t) e_{Z}(t)+b_{Z} U_{Z}(t), Z(0)=Z_{0}, \\
\frac{d}{d t}[Z(t)]=Z^{+}-Z^{-}
\end{gathered}
$$

where, for example, an technogenic object (TO): $Z^{+}=\gamma f(k), Z^{-}=\lambda(1-\alpha-\beta) f(k)+\delta z$, but for a technogenic regional economy as a whole (in case of mutual independence of the TO):

$$
Z^{+}=\sum_{1}^{n} \gamma_{i} f_{i}\left(k_{i}\right), \quad Z^{-}=\lambda \sum_{1}^{n}\left(1-\alpha_{i}-\beta_{i}\right) f_{i}\left(k_{i}\right)+\delta z \text {. }
$$

Ecological index equation:

$$
\begin{aligned}
\frac{d}{d t}[z(t)]-\delta_{z} z(t) & =E[\phi(t)]^{v_{1}}\left[\alpha_{L}^{1}(t) L(t)\right]^{v_{2}}\left[\alpha_{K}^{2}(t) K(t)\right]^{v_{3}}+ \\
& +\sigma_{z}(Z, t) e_{z}(t)+b_{z} U_{z}(t), z(0)=z_{0} .
\end{aligned}
$$

The equation of dynamics of the potential of the R\&D sector:

$$
\begin{aligned}
\frac{d}{d t}[\dot{\phi}(t)]-\delta_{\phi} \phi(t) & =G[\phi(t)]^{\gamma_{1}}\left[\alpha_{L_{1}}^{1}(t) L_{1}(t)\right]^{\gamma_{2}}\left[\alpha_{K}^{1}(t) K(t)\right]^{\gamma_{3}}[s(t)]^{\gamma_{4}}+ \\
& +\sigma_{\phi}(\phi, t) e_{\phi}(t)+b_{\phi} U_{\phi}(t), \phi(0)=\phi_{0} .
\end{aligned}
$$

Dynamics of the volume of skilled labor resources:

$$
\frac{d}{d t}\left[L_{1}(t)\right]-\delta_{L_{1}} L_{1}(t)=D[\phi(t)]^{\eta_{1} \cdot} \cdot\left[\alpha_{L_{1}}^{2}(t) L_{1}(t)\right]^{\eta}{ }^{2}+\sigma_{L_{1}}\left(L_{1}, t\right) e_{L_{1}}(t)+b_{L_{1}} U_{L_{1}}(t), \quad U_{L_{1}}(0)=U_{L_{1} 0},
$$

\section{Social index equation:}




$$
\begin{aligned}
\frac{d}{d t}[s(t)]-\delta_{s} s(t)= & H[\phi(t)]^{\nu_{1}}\left[\varepsilon_{L}^{1}(t) L(t)\right]^{\nu_{2}}\left[\varepsilon_{K}^{2}(t) K(t)\right]^{\nu_{3}}\left[\varepsilon_{z}^{3}(t) z(t)\right]^{v_{4}}+ \\
& +\sigma_{s}(s, t) e_{s}(t)+b_{s} U_{s}(t), U_{s}(0)=U_{0} .
\end{aligned}
$$

\section{Equation of the STP index:}

$$
\begin{gathered}
\frac{d}{d t}[\tau(t)]+\delta_{\tau} \tau(t)=Q\left[\dot{\phi}(t)+\delta_{\phi} \phi(t)\right]^{\beta_{1}}\left[\dot{L}_{1}(t)+\delta_{L_{1}} L_{1}(t)\right]^{\beta_{2}}\left[\dot{s}(t)+\delta_{s} s(t)\right]^{\beta_{3} *} \\
*\left[\dot{z}(t)+\delta_{z} z(t)\right]^{\beta_{4}}+b_{\tau} U_{\tau}(t), U_{\tau}(0)=U_{\tau 0} .
\end{gathered}
$$

\section{Dynamics of investment model I $(t)$ :}

$$
\begin{gathered}
I(t)=\exp (\omega t) \cdot F[K(t), L(t), R(t)], \\
\frac{d}{d t}[K(t)]+\alpha K(t)=I_{h}(t)-C(t)-D(t)-B(t)+ \\
+\sigma_{K}(K, t) e_{K}(t)+b_{j K} U_{j K}(t), K(0)=K_{0}, \\
\frac{d}{d t}\left[I_{h}(t)\right]+r I_{h}(t)=h_{0} I_{0}-\sigma_{I_{h}}\left(I_{h}, t\right) e_{I_{h}}(t)+b_{I_{h}} U_{I_{h}}, I_{h}\left(t_{0}\right)=h_{0} I\left(t_{0}\right)=h_{0} I_{0} .
\end{gathered}
$$

\section{Consumption dynamics model:}

$$
\begin{aligned}
d C(t) & =A(t) K(t) d t-(1-\alpha) K(t) d t+A(t) K(t) d W_{C}(t) \\
\text { or } \quad & \frac{d}{d t} C(t)=A(t) K(t)-(1-\alpha) K(t)+A(t) K(t) \sigma_{C}(C, t) e_{C}(t),
\end{aligned}
$$

where $Y(t)$ - the volume of "useful" output, $K(t)$ - capital, $L(t)$ - number of employees, $C(t)$ - volume of consumption, $Z(t)$ - volume of pollution ("harmful" output), $I(t)$ - investment, $R(t)$ - other resources, $D(t)$ - inputs for pollution abatement and monitoring, $B(t)$ - costs of hazard and sustainable development and $e(t)$ - the realization of a random variable obeying a standard normal law with an average equal to zero and a dispersion equal to one. Other notations are given in S.K.Ramazanov and K. Osterm (Ramazanov \& Sergienko, 2014; Osterm, 1970).

Random processes that are taken into account in the equations of system (1) - (12) are increments of Wiener processes distributed under a normal law with a mean zero and a dispersion proportional to the duration of a given time interval. Using the indicated property of increments of Verniers random processes and using the Euler-Marouei method, one can construct a discrete approximation of stochastic equations of system (1) - (12) in the form of linear recurrence relations.

Thus, in order to predict the development of an innovative economy on the basis of an Integral stochastic model of with control of growth dynamics can be represented as the following of relevant system of difference (discrete) equations (1p) - (12p):

$$
\Phi_{t+\Delta, j}(\circ)=\Phi_{t, j}(\circ)+\alpha_{j} \Phi_{t, j}^{+}(\circ)-\beta_{j} \Phi_{t, j}^{-}(\circ)+\sigma_{j}\left(\Phi_{t, j}, t\right) d W_{j t}+b_{j} U_{j t} .
$$




$$
\begin{gathered}
K_{t+\Delta}=K_{t}-\left(\alpha K_{t}-I_{t}+C_{t}+D_{t}+B_{t}\right) \Delta+\sigma_{K} \Delta \xi_{t}+b_{K} \Delta U_{K, t}, t=0,1, \ldots, \\
Y_{t}=F\left(K_{t}, L_{t}, R_{t}, \xi_{t}\right)=\left[\beta_{1} K_{t}^{\frac{\delta-1}{\delta}}+\beta_{2} L_{t}^{\frac{\delta-1}{\delta}}+\beta_{3} R_{t}^{\frac{\delta-1}{\delta}}\right]^{\frac{\delta}{\delta-1}}+\sigma_{Y} \xi_{t},
\end{gathered}
$$

or $\quad Y_{t}=A \tau_{t}\left[\left(1-\alpha_{K}^{1}(t)-\alpha_{K}^{2}(t)-\alpha_{K}^{3}(t)\right) K_{t}\right]^{\alpha_{1}}\left[\left(1-\alpha_{L_{2}}^{1}(t)-\alpha_{L_{2}}^{2}(t)\right) L_{2 t}\right]^{\alpha_{2}}+\sigma_{Y} \xi_{t}$,

$$
\begin{aligned}
L_{t+\Delta}= & L_{t}+\left(\gamma L_{t}-\gamma_{Z} Z_{t}+\gamma_{C} C_{t}\right) \Delta+\sigma_{L} \Delta \xi_{t}+b_{L} \Delta U_{L, t}, t=0,1,2, \ldots, \\
& R_{t+\Delta}=R_{t}+\left(\gamma_{R} R_{t}+\gamma_{K} K_{t}-Y_{t}-\gamma_{L} L_{t}\right) \Delta+\sigma_{R} \Delta \xi_{t}+b_{R} \Delta U_{R, t}, t=0,1, \ldots,
\end{aligned}
$$

or

$$
\begin{gathered}
R_{t+\Delta}=R_{t}+\left(d\left(K_{t}, L_{t}, R_{t}\right)+\gamma_{K} K_{t}-\gamma_{L} L_{t}-Y_{t}\right) \Delta+\sigma_{R} \Delta \xi_{t}+b_{R} \Delta U_{R, t}, t=0,1, \ldots, \\
Z_{t+\Delta}=Z_{t}+\left(g\left(Z_{t}\right)+f^{*}\left(C_{t}, K_{t}, L_{t}, R_{t}\right)\left(1-\eta C_{t}\right)\right) \Delta+\sigma_{Z} \Delta \xi_{t}+b_{Z} \Delta U_{Z, t}, t=0,1,2, \ldots,
\end{gathered}
$$

$z_{t+\Delta}=z_{t}+\left(\delta_{z} z_{t}+E\left[\phi_{t}\right]^{v_{1}}\left[\alpha_{L}^{1}(t) L_{t}\right]^{v_{2}}\left[\alpha_{K}^{2}(t) K_{t}\right]^{v_{3}}\right) \Delta+\sigma_{z} \Delta \xi_{t}+b_{z} \Delta u_{z, t}, t=0,1,2, \ldots$,

$$
\begin{gathered}
\phi_{t+\Delta}=\phi_{t}+\left(\delta_{\phi} \phi_{t}+G\left[\phi_{t}\right]^{\gamma_{1}}\left[\alpha_{L_{1}}^{1}(t) L_{1_{t}}\right]^{\gamma_{2}}\left[\alpha_{K}^{1}(t) K_{t}\right]^{\gamma_{3}}[s(t)]^{\gamma_{4}}\right) \Delta+ \\
+\sigma_{\phi} \Delta \xi_{t}+b_{\phi} \Delta u_{\phi, t}, t=0,1,2, \ldots,
\end{gathered}
$$

$$
\left.\left.L_{1 t+\Delta}=L_{1 t}+\left(\delta_{L_{1}} L_{1 t}+D \mid \phi_{t}\right]^{\eta_{1}} \cdot \mid \alpha_{L_{1}}^{2}(t) L_{1 t}\right]^{\eta_{2}}\right) \Delta+\sigma_{L_{1}} \Delta \xi_{t}+b_{L_{1}} \Delta u_{L_{1}, t}, t=0,1,2, \ldots,
$$

$$
\begin{aligned}
& s_{t+\Delta}=s_{t}+\left(\delta_{s} s_{t}+H\left[\phi_{t}\right]^{\nu_{1}} \cdot\left[\varepsilon_{L}^{1}(t) L_{t}\right]^{\nu_{2}} \cdot\left[\varepsilon_{K}^{2}(t) K_{t}\right]^{\nu_{3}} \cdot\left[\varepsilon_{z}^{3}(t) z_{t}\right]^{\nu_{4}}\right) \Delta+ \\
& +\sigma_{s} \Delta \xi_{t}+b_{s} \Delta u_{s, t}, t=0,1,2, \ldots
\end{aligned}
$$

$$
\begin{gathered}
\tau_{t+\Delta}=\tau_{t}+\left\{\delta_{\tau} \tau_{t}+Q\left[\frac{\phi_{t+\Delta}-\phi_{t}}{\Delta}+\delta_{\phi} \phi_{t}\right]^{\beta_{1}}\left[\frac{L_{1 t+\Delta}-L_{1 t}}{\Delta}+\delta_{L_{1}} L_{1 t}\right]^{\beta_{2}}\left[\frac{s_{t+\Delta}-s_{t}}{\Delta}+\delta_{s} s_{t}\right]^{\beta_{3}} *\right. \\
\left.*\left[\frac{z_{t+\Delta}-z_{t}}{\Delta}+\delta_{z} z_{t}\right]^{\beta_{4}}\right\} \Delta+\sigma_{\tau} \Delta \xi_{t}+b_{\tau} \Delta u_{\tau, t}, t=0,1,2, \ldots, \\
K_{t+\Delta, h}=K_{t, h}-\left(\alpha K_{t, h}+I_{h t}-C_{t}-D_{t}-B_{t}\right) \Delta+\sigma_{K} \Delta \xi_{t}+b_{K_{h}} \Delta U_{K_{h}, t}, t=0,1, \ldots, \\
I_{h t+\Delta}=I_{h t}-\left(r I_{h}(t)+h_{0} I_{0}\right) \Delta+\sigma_{I_{h}} \Delta \xi_{t}+b_{K_{h}} \Delta U_{K_{h}, t}, t=0,1, \ldots, I_{h, 0}=h_{0} I(0)=h_{0} I_{0}, \\
C_{t+\Delta}=C_{t}+\left\{A_{t} K_{t}-(1+\delta) K_{t}\right\} \Delta+A_{t} K_{t} \sigma_{C} \Delta \xi_{t}+b_{C} \Delta U_{C, t}, t=0,1, \ldots,,
\end{gathered}
$$

where $\Delta$ - step the time interval at which we will make calculations; $\xi_{\mathrm{t}}$ is the realization of a random variable that obeys a standard normal law with an average equal to zero and a dispersion equal to one. We also note that here $\mathrm{z}(\mathrm{t}), \mathrm{s}(\mathrm{t}), \tau(\mathrm{t}), \phi(\mathrm{t})$ are the indices of the corresponding basic indicators (Galitsin \& Ramazanov, 2017). 
We note that for the computer realization of stochastic difference (discrete) equations (1p) - (12p) it is necessary to pass to the average variables $\mathrm{x}(\mathrm{t})=\left(\mathrm{Y}(\mathrm{t}), \mathrm{K}(\mathrm{t}), \mathrm{L}(\mathrm{t}), \mathrm{R}(\mathrm{t}), \mathrm{Z}(\mathrm{t}), \mathrm{z}(\mathrm{t}), \mathrm{s}(\mathrm{t}), \tau(\mathrm{t}), \phi(\mathrm{t}), I_{h}(t), C(t)\right)$, that is their mathematical expectations, $\bar{U}_{t}$ and $\bar{u}_{t}$ - relevant control vectors.

Optimal control / management criteria options. Eco-economic development strategy selection criterion:

$$
E\left[J\left(C, Y, D, B, \bar{U}_{t}\right)\right] \rightarrow \max
$$

where $J\left(C, Y, D, B, \bar{U}_{t}\right)$ - goal function, and $E$ - expectation value symbol. Consequently, the hierarchical optimization model of the system is obtained in the following form:

$$
\{\mathrm{E}\{Z\} \rightarrow \min , \mathrm{E}\{K\} \rightarrow \max , \dot{Z}=\chi(Z, K, L, R, c), \dot{K}=\phi(K, L, R, c) .
$$

In case of a "small" integral management model, utility function (UF) is a function of the parameters / variables $\tilde{u}\left(\alpha_{1}, \alpha_{2}, \alpha_{3}, \alpha_{4}\right)$, where $\left\{\alpha_{k}(t), k=1, \ldots, 4\right\}$ - shares of costs for non-manufacturing, environmental costs, R\&D efforts, for safety and security, innovation and information technologies, etc., and then the following relationship will be the optimality criterion:

$$
\Lambda(c, k, z, L, \tau, S)=\int_{t_{0}}^{T} \tilde{u}\left(\alpha_{1}, \alpha_{2}, \alpha_{3}, \alpha_{4}\right) \exp (-\theta t) d t \rightarrow \max _{\left\{\alpha_{i}\right\} \in \tilde{\Omega}} .
$$

To resolve the EEC tasks on the basis of the presented stochastic and deterministic models, one can use the known classical methods of optimal control with restrictions. Generally, the optimization criterion can be represented as $\Lambda(\vec{a})=\int_{t_{0}}^{T} \tilde{u}\left(\alpha_{1}, \alpha_{2}, \alpha_{3}, \alpha_{4}, \ldots\right) \exp (-\theta t) d t \rightarrow \max _{\left\{\alpha_{i}\right\} \in \tilde{\Omega}}$. Therefore, socio-ecological, innovation and other optimality criteria are also required integrally!

Control synthesis task in stochastic systems. Let us consider the optimal management synthesis task in stochastic linear systems (Sultan Ramazanov etc, 2019).

Phase state of the system means the vector $x=\left(x_{1}, x_{2}, \ldots, x_{n}\right)$, where $x_{i}, i=1, \ldots, n$ - aggregate of data describing the i-th sector of the system. Let us assume that all the sectors are provided with some management levers: $u=\left(u_{1}, u_{2}, \ldots, u_{n}\right)$.

Each of the listed parameters, in its turn, represents a vector composed of the numeric values of different characteristics of the system dynamics. Let us assume that $\left[\mathrm{t}_{0}, \mathrm{t}_{\mathrm{k}}\right]$ - reviewed system development period. Let us designate as $\xi$ the vector of some additional parameters determined by means of forecasting using statistical data of the system, or which are constants. Consequently, the dependence is studied of each variable $x_{i}, i=1, \ldots, n$ from the managing variables $u_{i}$ of the system states and the vector of parameters $\xi$.

The linearized system model looks as follows: 


$$
\dot{x}(\xi, t)=A(\xi) x(\xi, t)+B(\xi) u(\xi, t), \quad x(\xi, t) \in R^{n}, u(\xi, t) \in R^{m}, A(\xi) \in R^{n \times m}, B(\xi) \in R^{n \times m} ;
$$

where $A(\xi)=\left\lfloor A_{i j}(\xi)\right\rfloor B(\xi)=\left\lfloor B_{i j}(\xi)\right\rfloor$ - matrices with parametric uncertainty;

$x(\xi, t)=\left\lfloor x_{i}(\xi, t)\right]$ - system state vector;

$u(\xi, t)=\left[u_{i}(\xi, t)\right]$ - management vector; $\xi$ - vector of stochastic processes.

The task of optimal management synthesis for a stochastic dynamic system is posed as follows: to find an optimal management law in the form of (Osterm, 1970; Pshikhopov, 2009; Sultan Ramazanov et al, 2019): $u(\xi, t)=-L \hat{x}(\xi, t)$ and the objective functional for optimization (minimization) should be predetermined in the following form:

$$
J=\int_{\Omega}\left\{\int_{0}^{t_{k}}\left(x^{T}(\xi, t) \Theta x(\xi, t)+u^{T}(\xi, t) R u(\xi, t)\right) d t\right\} \rho(\xi) d \xi .
$$

For example, the optimization problem with the terminal control criterion can be represented as the problem of minimizing the quadratic functional:

$$
J[u(t)]=x^{T}\left(t_{f}\right) \Phi x\left(t_{f}\right)+\int_{0}^{t_{f}}\left[x^{T}(t) \Omega(t) x(t)+u^{T}(t) R(t) u(t)\right] d t
$$

and the optimal control problem itself will look like: $\bar{J}[u(t)]=E\{J[u(t)]\} \Rightarrow$ min

Here the symbols " $T$ " stands for the transpose operation, and "E" stands for the operation for determining the mathematical expectation ("averaging").

In a simple case, linear observation equation may be used in the following form: $y(t)=H(t) x(t)+\eta(t)$. In this equation, the observation $H(t)$ is represented by a stochastic observation matrix, which can be preset in practical terms, and $\eta(t)$ is the "white noise" type process, which can be preset based on statistical data. In doing so, two independent tasks are to be resolved based on the separation principle (Ramazanov, 1982; Osterm, 1970; Pshikhopov, 2009).

In the early papers of the first author of this paper, the task of optimal evaluation (filtration) under the conditions of multiplicative-additive mixtures was resolved using the integral description of the filter (Ramazanov, 1982).

However, the filtration task can also be conveniently resolved using the Kalman filter for the linear case and the Stratonovich filter for the non-linear right part of the dynamic's equation. State estimates are found as the conventional average values with the building and solution of the non-linear dispersion equations of the Riccati type. The filter gives a solution for the stochastic differential equation. It can be implemented in the form of the known closed loop system for the distribution density of the initial conditions. The obtained state estimate $\hat{x}(t)$ is used in resolving the other task - optimal management of the type $\hat{u}(t)=-L(t) \hat{x}(t)$ 
As mentioned above, the optimal management task is usually set on the basis of the Bellman principle or the maximum principle.

\section{CONCLUSIONS}

Based on the use of modern methods, models, information and innovative technologies for prediction of the state of nonlinear dynamics of ecological - economic and social - humanitarian systems, integrated stochastic models of objects and processes suitable for systems of systemic crises have been developed and investigated. The paper considers the integration of many spheres and sectors of activity of modern complex systems such as SEEHS, which function and develop in difficult conditions of instability and crises. As a result of complex formalization, one of the variants of an integrated social, ecological, economic and innovation nonlinear model of dynamics in the form of a system of differential and functional stochastic equations is obtained. To predict the development of the state of the innovation economy, an integrated stochastic nonlinear model of growth dynamics developed and investigated is developed and investigated, which is suitable for the minds of risks and crises. The aspects of integration of many spheres and sectors of activity of modern complex systems, which function and develop in the current conditions of instability, are considered in this paper. The prospect of further research is the presentation of the proposed integral model in the phase space with observation equations, the development of filters and optimal control algorithms.

The paper deals with the problem of sustainable development and innovative integral modeling approach in the management of technogenic objects and processes as a system of socio-eco-economic and humanitarian type. Based on the use of information and innovation technologies in order to forecast the non-linear dynamics of eco-economic and socio-humanitarian systems, integrated stochastic models of objects and processes were developed and studied, suitable for the conditions of systemic crises.

\section{Conflict of interests}

The authors declare no conflict of interest.

\section{Bibliography}

Action program. Agenda 21. Adopted by the United Nations Conference on Environment and Development, Rio de Janeiro, 3-14, 1992. Access mode: http://www.un.org/russian/conferen/wssd/agenda21/

Arshinov V.I., Budanov V.G. Complexity paradigm and socio-humanitarian projections of convergent technologies // Philosophy Issues, 2016. - No. 1, P. 59-70.

Chuprov S.V. Sustainability management of production systems: theory, methodology, practice / S.V. Chuprov. - 2nd ed., Rev. and add. - Irkutsk: Publishing house of BSUEP, 2012. - 354 p.

Convergence of Knowledge, Technology and Society: Beyond Convergence of Nano-Bio-Info-Cognitive Technologies/ M.C. Roco, W.S. Bainbridge, B. Tonn, G. Whitesides. Dordrecht, 2013. URL: http://www.wtec.org/NBIC2/Docs/WTEC-Convergence\%20of\%20KTS-010814.pdf 
Digital economy and "Industry 4.0": problems and prospects: proceedings of a scientific-practical conference with international participation / ed. Dr. econ. sciences, prof. A.V. Babkina. - SPb.: Publishing house of the Polytechnic University, 2017. - 685 p.

Galitsin V.K., Ramazanov S.K. Integral Stochastic Nonlinear Model of the Dynamics of an Innovative Economy, Scientific-Analytical Journal "Modeling and Information Systems in Economics", Sat. sciences works, Main Ed. V.K. Galician - Kyiv: KNEU, 2017. P. 50-64.

Green Economy (EU Experience and Ukraine's Practice in the Light of III and VI Industrial Revolutions) (textbook) print. Sums: University Book, 2017. - 342 p.

Grigorkiv V.S. Simulation of Multisectoral Ecological Economic System // Cybernetics and System Analysis. - 1999. № 3. - P. 147-157.

Gryshova, I.; Petrova, M.; Tepavicharova, M.; Diachenko, A.; Gutsul, T. 2019. A model for selection of a management team to ensure the sustainability and development of the business organizations, Entrepreneurship and Sustainability Issues 7(1): 690-703. http://doi.org/10.9770/jesi.2019.7.1(49)

Information and innovation management technologies in ecological and economic systems. Monograph / Ed. prof. S. K. Ramazanova. - Kyiv: KNEU them. V. Hetman, 2019. - 220 p.

Kapitsa S.P. Human capital in the format of the digital economy: Intern. scientific Conf., dedicated to the 90th anniversary of S.P. Kapitsa, Moscow, February 16, 2018: Sat. reports. - M.: Ed. house RosNOU. - 2018. - 432 p.

Koval, V.; Duginets, G.; Plekhanova, O.; Antonov, A.; Petrova, M. 2019. On the supranational and national level of global value chain management. Entrepreneurship and Sustainability. Issues 6(4): 1922-1937. http://doi.org/10.9770/jesi.2019.6.4(27),

Koval, V.; Sribna, Y.; Mykolenko, O.; Vdovenko, N. (2019). Environmental concept of energy security solutions of local communities based on energy logistics. 19th International Multidisciplinary Scientific GeoConference SGEM 2019, 19(5.3), 283-290. https://doi.org/0.5593/sgem2019/5.3/S21.036

Kovalchuk M.V., Naraikin O.S., Yatsishina E.B. The convergence of science and technology - a new stage in scientific and technological development // Questions of Philosophy, 2013, No. 3.

Kurmanov N.A., Toksanova A.N. Mukhamedzhanov A.A., Syrlybayeva N.Sh.; M.M., Petrova. (2018). Analysis of efficiency of innovation activities in the countries of the Eurasian Economic Union. The Journal of Economic Research \& Business Administration, [S.1.], v. 126, n. 4, p. 35-51, 2018. eISSN 2617-7161. pISSN: 1563-0358. Al-Farabi Kazakh National University, Available at: https://be.kaznu.kz/index.php/math/article/view/2026

Lecturer V.A. Rationality, social technologies and the fate of man // Epistemology and philosophy of science, 2011. No.3. P.35-48.

Levashova, L. (2011A). Marketing wewnętrzny w kontekście motywowania pracowników, w: Świerszcz K. i Nowacki $W .$, Ksztaltowanie lojalności klientów $w$ teorii $i$ w praktyce. Warszawa: Wydawnictwo Warszawska Wyższa Szkoła Ekonomiczna.

Levashova, L. (2011B). Rozwój kariery zawodowej pracowników w aspekcie innowacji, w: Innowacje przedsiębiorstw a satysfakcja klientów $w$ teorii $i$ w praktyce, pod redakcja naukowa Świerszcz $K$. $i$ Śliwa J. Warszawa: Wydawnictwo Społeczna Wyższa Szkoła Przedsiębiorczosci i Zarządzania w Łodzi.

Lukjanova, J., Sushchenko, O., Zima, O. (2019). Educated and competent staff as important factor of innovation development of machine-building and metalworking industry in Latvia, ISPCIME-2019. MATEC Web of Conferences, EDP Sciences, vol.297 (06006), 2019, DOI: https://doi.org/10.1051/matecconf/201929706006

Melnyk, L. Green economy: best eu practices for Ukraine [Текст] / L. Melnyk, I. Dehtyarova, O. Kubatko // Economics for Ecology ISCS'2015: Proceedings of the XXI International Scientific Conference, Sumy, 6-7 May 2015 / Ed. Smolenikov, A.A. Iskakov. - Sumy: SSU, 2015. - P. 62-64.

NBIC- technology: innovative civilization of the XXI century / A.K. Kazantsev, V.N. Kiselev, D.A. Rubvalter, O.V. Rudensky. - M., 2012. - 384 p.

Nenkov, N., Sushchenko, O., Dyachenko Y. (2017) Role of chief information officer within the system of human resource development in the service organizations (tourism) // Economic Annals-XXI. - Issue 5-6. - Vol. 165. - P. 97-103.

Osterm K. Introduction to the stochastic control theory. - M.: Mir, 1970. - 326 p.

Pshikhopov V.Kh., Medvedev M.Yu. Evaluation and management in complex dynamic systems. - M.: FIZMATLIT, 2009. - 295 p. 
Ramazanov S.K. Innovative technologies of crisis management of economic systems: monograph / S.K. Ramazanov, G.O. Nagyon, N.I. Crystal, O.P. Stepanenko, L.A. Timashova; Ed. prof. S.K. Ramazanova. - Lugansk - Kiev: issue of SNU to the name V. Dahl, 2009. - 584 p.

Ramazanov S.K., Rogoza M.E., Musayeva E.K.. Nonlinear models and analysis of complex systems: Tut. guide: In 2 hrs / Team of authors; in a row. prof. S.K. Ramazanova. Poltava: PUET, 2010. - Part 1. - 300 p.; Part 2. - 322 p.

Ramazanov S.K. Modeling of social - ecological - economic dynamics in an unstable environment. WITH. S.K. Ramazanov, Information Sciences and Systems Science (ISN-2015): Materials of the VI All-Ukrainian Scientific and Practical Conference on International Participation (Poltava, 19-21, 2015). - Poltava: PUTE, 2015. - P. 56-62.

Ramazanov S.K. The digital economy and the problem of sustainable development: information tools and converging technologies. - P. 147-150 // Modern problems of modeling of socio-economic systems. Mater. X International IP of the Internet Conference April 5-6, 2018, X.: KhNEU named after S. Kuznets, 2018. - 224 p.

Ramazanov S.K., Stepanenko O.P., Chernyak O.I, Tishkov B.O. Forecasting models and technologies and the problem of designing the future: state analysis and individual results. - P. 164-191 // Actual problems of forecasting the development of socio-economic systems: Monograph / Ed. O.I. Chernyaka, P.V. Zakharchenko. - Melitopol: 2019. $456 \mathrm{p}$.

Ramazanov S.K., Stepanenko O.P., Tishkov B.O., Honcharenko O.G. Problem of forecasting and innovation economics control based on integrated dynamics model. - P. 91-106// «Information systems and innovative technologies in project and program management» [Text]: Collective monograph edited by I. Linde, I. Chumachenko, V. Timofeyev - Riga: ISMA, 2019. - 339 p.

Ramazanov S.K. Tools of ecological and economic management of the enterprise. Monograph, S.K. Ramazanov Donetsk: South-East Ltd., Ltd., 2008. - 351 p.

Ramazanov S.K., Burbelo O.A., Vitlinsky V.V., and others. Risks, security, crises and sustainable development in the economy: methodologies, models, methods of management and decision-making. Monograph / Under the congregation. Ed. prof. S.K. Ramazanova - Lugansk: View of "Nulledzh", 2012. - 948 p.

Ramazanov S.K., Modeling of social - ecological - economic dynamics in an unstable environment. S.K. Ramazanov, Information Sciences and Systems Science (ISN-2015): Materials of the VI All-Ukrainian Scientific and Practical Conference on International Participation (Poltava, 19-21, 2015). - Poltava: PUTE, 2015.

Ramazanov S.K., Sergienko A.V. Socio-ecological-economic modeling and management of man-made regional production in a crisis; Modeling and information technologies in the study of socio-economic systems: theory and practice: Monograph, Collected authors, Ed. doctor of sciences, prof. V.S. Ponomarenko, doctor of economics, prof. T.S. Klebanov - Berdyansk, 2014. - 604 p.

Ramazanov S.K., Stemplevskaya L.V. Sustainable development and integrated model of socio-ecological-economic management in the conditions of crisis, Proceedings of the IV International scientific-practical conference "Mechanisms, strategies, models and technologies of management of economic systems under conditions of integration processes: theory, methodology, practice", 6-8 October 2017, FOP Storozhuk OV, Khmelnitsky 2017/10, P. 63-64.

Ramazanov S.K. Estimation and identification of stochastic multiplicative additive mixtures / Abstract. diser. for the competition step. Ph.D., Kiev, 1982. -24 p.

Ramazanov, C., Chernyak, O., Tishkov, B., Ahmedov R. and Oleksandr Honcharenko. Non-linear forecasting of the state of a socio-eco-oriented innovative economy in the conditions of systemic crises. SHS Web of Conferences Volume 65 (2019). The 8th International Conference on Monitoring, Modeling \& Management of Emergent Economy (M3E2 2019). Odessa, Ukraine, May 22-24, 2019. - P. 181-193.

Schwab K. The Fourth Industrial Revolution. - M.: Eksmo, 2016. - 208 p.

Sergienko AV Models of Socio-Ecological and Economic Management of Technogenic Regional Production in Crisis // Dissertation abstract for the degree of Candidate of Economic Sciences - Zaporizhia: KPU, 2017. - $23 \mathrm{p}$.

Solovyov V.I. Economic and mathematical modeling of the software market: a monograph. V.I. Soloviev; GUU - M.: Vega-Info, 2009. - $176 \mathrm{p}$

Stemplewska, L. (2011). Wpływ otoczenia ekonomicznego na efektywność systemów motywacyjnych w przedsiębiorstwach. Warszawa: Wydawnictwo Elipsa.

Sushchenko, O. (2016). Creation of innovation clusters as a line of enterprise competitiveness improvement in the field of foreign economic activity, Actual Problems of Economics, 177(3), 191-198 
Sushchenko O. A., (2015), Global shifts as aspects of globalization impact on foreign economic activity management // Contribution to International Economy, Vol. 1, № 2, p. 41-48.

Sushchenko O., Trunina I., Klok O., Loseva O., (2019), Management technologies of ensuring environmental protection as the territory development strategic priority / // (IES2018) SHS Web Conf. Volume 61, Web of Science. doi: https://doi.org/10.1051/shsconf/20196101026

Sushchenko, O., I. Trunina, (2016), Creation of Innovation Clusters as a Line of Enterprise Competitiveness Improvement in the Field of Foreign Economic Activity, Actual Problems of Economics, 3(177), p. 191-198.

Sustainable development: theory, methodology, practice: textbook / ed. prof. L. G. Melnik. - Sumy: University Book, 2009. - 1216 p.

Tew Bloommart, Stefan van den Brook, Eric Koltof. Fourth industrial revolution and business. How to compete and develop in an era of singularity. Translation from English - M.: Alpina Publisher, 2019. - 204 p. - Access mode: http://proxylibrary.hse.ru:2117/en/library/book/18119

Vagapova Ya.Ya. Modeling of economic growth taking into account environmental and social factors. Ya.Ya. Vagapova. - M.: MAKS Press, 2007. - 128 p.

Yankovyi, O., Goncharov,Yu.,Koval, V., \&Lositska, T. (2019). Optimization of the capital-labor ratio on the basis of production functions in the economic model of production. Naukovyi Visnyk Natsionalnoho Hirnychoho Universytetu, 4, 134-140.

Yeshchenko, M., Koval, V., \&Tsvirko, O. (2019). Economic policy priorities of the income regulation. Espacios, 40 (38), 11.

Zerkalov D.V. Problems of sustainable management. An anthology. - Kiev: Basis, 2012. - 1008 p.

Zgurovsky M.Z., Statyukha G.A. A systematic approach to the assessment and management of sustainable development of society // System technology and information technology, 2007, No. 3. - P. 7-27.

\begin{abstract}
About the authors:
Sultan RAMAZANOV, Doctor of Technical Sciences, Doctor of Economics, Professor Emeritus of East Ukrainian National University V. Dalia, Honoured Worker of Science and Technology of Ukraine (Ukraine), Academician of academies: MAI, MANEB, AENA, TAU, ANTU. Professor of the Department of Information Systems in Economics, Institute of Information Technology in Economics, Vadym Hetman Kyiv National Economics University, Kyiv, Ukraine. Research interests: nonlinear modeling in socio-economic and environmental systems, intelligent systems and modeling technologies, control and forecasting of environmental and socio- economic processes and systems, management and decision making.
\end{abstract}

ORCID ID: $\underline{\text { https://orcid.org/0000-0002-8847-6200 }}$

Mariana PETROVA, Professor, D.Sc. in Physics and Mathematics, assoc.prof. St. Cyril and St. Methodius University of Veliko Tarnovo, Bulgaria; Professor Economics and Management in Department of Management, ISMA University, Riga, Latvia. Research interests: management of IT processes, project and services, business administration, intelligent systems and modeling technologies, information systems and innovations, sustainable development.

ORCID ID: $\underline{\text { https://orcid.org/0000-0003-1531-4312 }}$ 